\title{
CrystEngComm
}

Check for updates

Cite this: CrystEngComm, 2020, 22, 5031

Received 19th December 2019, Accepted 29th June 2020

DOI: 10.1039/c9ce02003a

rsc.li/crystengcomm

\section{Crystallization of $\mathrm{BaF}_{2}$ from droplets of phase separated glass - evidence of a core-shell structure by ASAXS}

\author{
Armin Hoell, (D)*a Vikram Singh Raghuwanshi, ${ }^{\text {a }}$ Christian Bocker, ${ }^{\text {b }}$ \\ Andreas Herrmann, ${ }^{c}$ Christian Rüssel (iD) ${ }^{* b}$ and Thomas Höche (iD ${ }^{d}$
}

\begin{abstract}
Glasses with the mol\% compositions $1.88 \quad \mathrm{Na}_{2} \mathrm{O} \cdot 15.04 \quad \mathrm{~K}_{2} \mathrm{O} \cdot 7.52 \mathrm{Al}_{2} \mathrm{O}_{3} \cdot 69.56 \mathrm{SiO}_{2} \cdot 6.00 \mathrm{BaF}_{2}$ and 1.88 $\mathrm{Na}_{2} \mathrm{O} \cdot 15.03 \quad \mathrm{~K}_{2} \mathrm{O} \cdot 7.52 \quad \mathrm{Al}_{2} \mathrm{O}_{3} \cdot 69.52 \quad \mathrm{SiO}_{2} \cdot 6.00 \quad \mathrm{BaF}_{2} \cdot 0.05 \mathrm{SmF}_{3}$ were studied using X-ray diffraction, transmission electron microscopy, and anomalous small-angle $X$-ray scattering (ASAXS). While the glass doped with samarium showed liquid/liquid phase separation of droplets with sizes of around $100 \mathrm{~nm}$, the glass without samarium did not. The samples were annealed at $580{ }^{\circ} \mathrm{C}$ or at $600{ }^{\circ} \mathrm{C}$ which led to the crystallization of cubic $\mathrm{BaF}_{2}$. The X-ray diffraction patterns showed strongly broadened lines. Hence, the $\mathrm{BaF}_{2}$ crystals possess sizes in the $\mathrm{nm}$ range. ASAXS gave evidence of a core shell structure. In agreement with earlier studies, it is assumed that the shell acts as a diffusion barrier that hinders crystal growth. Surprisingly, the cores and shells from the crystallization of the homogeneous glass and from the second glass, which is Sm-doped and shows liquid/liquid phase separation, both possess similar dimensions, even though the origin of the barrier is very different. The doped samples show long luminescence lifetimes of nearly $5 \mathrm{~ms}$ at a wavelength of $600 \mathrm{~nm}$, which is nearly as long as those in fluoride phosphate glasses.
\end{abstract}

\section{Introduction}

In the past few years, the formation of nanocrystals from glasses was intensively studied. ${ }^{1-4}$ It has been shown that a prerequisite for the formation of nanocrystals is a core shell structure. ${ }^{5,6}$ This can be achieved if during the course of nucleation and subsequent crystal growth the core becomes successively enriched in network modifying oxides or other less mobile components, leading to increased viscosity in the depleted residual glassy phase. ${ }^{7-9}$ This results in a drastic decrease in the diffusion coefficients in the shell and in a deceleration of crystal growth. In some cases, the crystals do not grow any further within the time scale of the experiments of some ten hours. ${ }^{10-13}$ A very narrow crystal size distribution is observed, which is even narrower than the predicted Lifshitz-Slyozov-Wagner (LSW) distributions obtained from

\footnotetext{
${ }^{a}$ Institute for Nanospectroscopy, Helmholtz-Zentrum Berlin für Materialien und Energie, Hahn-Meitner-Platz 1, D-14109 Berlin, Germany.

E-mail: hoell@helmholtz-berlin.de

${ }^{b}$ Otto-Schott-Institut, Friedrich Schiller Universität Jena, Fraunhoferstraße 6, 07743 Jena, Germany. E-mail: ccr@uni-jena.de

${ }^{c}$ Kazuo Inamori School of Engineering, New York State College of Ceramics, Alfred University, 2 Pine Street, Alfred, NY, 14802, USA

${ }^{d}$ Optical Materials and Technologies, Fraunhofer Institute for Microstructure of Materials and Systems IMWS, Walter-Hülse-Straße 1, D-06120 Halle, Germany
}

Ostwald ripening. ${ }^{14,15}$ Previously, these core shell structures were predicted based on the chemical composition of the glass and the formed crystalline phases as well as the measured changes in the glass transition temperatures of partially crystalline samples. In the past decade, new aberration-corrected transmission electron microscopes (TEMs) have been developed that are able to detect the shell directly using electron energy loss spectroscopy (EELS) ${ }^{16}$ or energy-dispersive X-ray spectrometry (EDXS). ${ }^{17-19}$ Moreover, the formed core shell structures were also confirmed with the data from anomalous small-angle X-ray scattering (ASAXS). ${ }^{20}$

Up to now, core shell structures have been predominantly observed during homogeneous nucleation of rare earth fluorides $^{18}$ and earth alkaline fluorides. ${ }^{8-16,20-23}$ These fluoride nanocrystals are good hosts for rare earth elements with interesting luminescence and up-conversion properties. Narrow size distribution is an important prerequisite for transparency in the visible light spectrum, which is required for applications in optics and photonics.

In lithium aluminosilicates, $\mathrm{ZrTiO}_{4}$ acts as a nucleation agent. The first step of the nucleation process is the formation of an amorphous droplet-like phase, and subsequently $\mathrm{ZrTiO}_{4}$ precipitates. This also leads to the formation of a core shell structure. ${ }^{7,24}$ The formation of liquid/liquid phase separation with a droplet structure is observed in the case of some oxyfluoride glasses. ${ }^{21,22}$ Already 
minor quantities of rare earth elements may lead to phase separation. It has been shown for an oxyfluoride glass from which $\mathrm{BaF}_{2}$ can be precipitated that addition of rare earth oxides in a concentration as small as 0.05 mol\% leads already to the formation of droplet phase separation. ${ }^{23}$

In the present paper, the effect of $0.05 \mathrm{~mol}^{\circ} \mathrm{SmF}_{3}$ on the crystallization of a glass with a composition of $1.88 \mathrm{Na}_{2} \mathrm{O}-$ $15.04 \quad \mathrm{~K}_{2} \mathrm{O}-7.52 \quad \mathrm{Al}_{2} \mathrm{O}_{3}-69.56 \quad \mathrm{SiO}_{2}-6 \quad \mathrm{BaF}_{2} \quad$ is studied predominantly using the XRD, ASAXS and TEM methods.

\section{Experimental procedure}

Glasses with the compositions (in mol\%) $1.88 \mathrm{Na}_{2} \mathrm{O} \cdot 15.04$ $\mathrm{K}_{2} \mathrm{O} \cdot 7.52 \mathrm{Al}_{2} \mathrm{O}_{3} \cdot 69.56 \mathrm{SiO}_{2} \cdot 6 \mathrm{BaF}_{2}$ (denoted as sample A) and $1.88 \mathrm{Na}_{2} \mathrm{O} \cdot 15.03 \mathrm{~K}_{2} \mathrm{O} \cdot 7.52 \mathrm{Al}_{2} \mathrm{O}_{3} \cdot 69.52 \mathrm{SiO}_{2} \cdot 6 \mathrm{BaF}_{2} \cdot 0.05 \mathrm{SmF}_{3}$ (denoted as sample $\mathrm{B}$ ) were studied (Table 1). They were melted from reagent grade $\mathrm{Al}(\mathrm{OH})_{3}, \mathrm{~K}_{2} \mathrm{CO}_{3}, \mathrm{Na}_{2} \mathrm{CO}_{3}, \mathrm{BaF}_{2}$, $\mathrm{BaCO}_{3}$ and $\mathrm{SiO}_{2}$ (quartz) in quantities of $200 \mathrm{~g}$ in a platinum crucible at $1590{ }^{\circ} \mathrm{C}$, kept for $1.5 \mathrm{~h}$. The glass melt was cast on a copper block and transferred to a furnace preheated to 450 ${ }^{\circ} \mathrm{C}$. The furnace was subsequently switched off and the glass samples were allowed to cool down slowly. This was done to reduce mechanical stresses. The temperature of $450{ }^{\circ} \mathrm{C}$ was below the glass transition temperatures of the studied glasses (473 ${ }^{\circ} \mathrm{C}$ for glass $\mathrm{A}$ and $485{ }^{\circ} \mathrm{C}$ for glass $\mathrm{B}$ ) and hence nucleation should not occur. For crystallization, compact sample pieces of these glasses were annealed for $20 \mathrm{~h}$ at temperatures of 580 or $600{ }^{\circ} \mathrm{C}$.

From annealed and subsequently powdered samples, XRD patterns were recorded using a Siemens D5000 diffractometer with CuK $\alpha$ radiation $(\lambda=0.154 \mathrm{~nm})$, a step size of $0.02^{\circ}$ and a $10 \mathrm{~s}$ time/step ratio. The measurement was carried out with a grain size fraction of $<63 \mu \mathrm{m}$.

The glass transition temperature $T_{\mathrm{g}}$ was measured by dilatometry on cylindrically shaped samples using a Netzsch DIL 402 PC equipped with a silica-glass measurement system. A heating rate of $5 \mathrm{~K} \mathrm{~min}^{-1}$ was applied. Differential scanning calorimetry (DSC) was performed with a Linseis DSC PT-1600 and a heating rate of $10 \mathrm{~K} \mathrm{~min}^{-1}$.

The microstructures of the glasses were further studied by transmission electron microscopy (TEM, Hitachi H 8100) using a replica technique. A carbon-platinum-iridium film was evaporated on the surface and subsequently removed by floating off on acid (a mixture of hydrofluoric and nitric acid) while the film retained the original topography. ${ }^{25}$ This technique is suitable to visualize liquid/liquid phase separation in glasses.

Additionally, TEM analyses from the bulk material were performed with an FEI TITAN ${ }^{3}$ G2 80-300 microscope

Table 1 Chemical compositions of the studied samples

\begin{tabular}{lllllll}
\hline & \multicolumn{7}{c}{ Chemical composition in mol\% } \\
\cline { 2 - 7 } & $\mathrm{Na}_{2} \mathrm{O}$ & $\mathrm{K}_{2} \mathrm{O}$ & $\mathrm{Al}_{2} \mathrm{O}_{3}$ & $\mathrm{SiO}_{2}$ & $\mathrm{BaF}_{2}$ & $\mathrm{SmF}_{3}$ \\
\hline Sample A & 1.88 & 15.04 & 7.52 & 69.56 & 6.00 & - \\
Sample B & 1.88 & 15.03 & 7.52 & 69.52 & 6.00 & 0.05
\end{tabular}

equipped with a high-angle annular dark field detector (HAADF, Fischione Model 3000). For elemental analyses, energy-dispersive X-ray spectroscopy (EDXS) was performed using a Super-X EDX detector, equipped with four silicon drift detectors (FEI Company).

In order to prepare electron transparent samples, the mechanical wedge-polishing approach was applied. First, a dedicated grinding and polishing tool (Multiprep, Allied company) was used. After finishing this preparation, lowenergy $\mathrm{Ar}^{+}$ion broad-beam milling (precision ion polishing system PIPS, Gatan company) was performed followed by selective carbon coating for mitigation of electrostatic charging. ${ }^{26}$

The as-prepared and annealed glass samples were studied by SAXS and ASAXS. The thicknesses of the polished sample sheets on both sides varied between 30 and $50 \mu \mathrm{m}$, which is required to achieve a sufficiently high X-ray transmission. The SAXS measurements were conducted at $4900 \mathrm{eV}$, an energy far below the Barium $\mathrm{L}_{3}$ X-ray absorption edge $\left(\mathrm{Ba} \mathrm{L}_{3}\right)$. The ASAXS experiments were carried out on all the samples by using 4 different energies close to the $\mathrm{Ba} \mathrm{L}_{3}$ absorption edge $(5247 \mathrm{eV})$ at the 7T-MPW-SAXS beamline at BESSY II, Helmholtz Zentrum Berlin (HZB) Synchrotron, Berlin, Germany. X-ray energies of 4900, 5177, 5234 and $5244 \mathrm{eV}$ were used. For data collection, we used a gas filled multi-wire proportional counter (MWPC) area detector with quadratic pixels having sizes of $207 \mathrm{~mm}^{2}$. The samples were measured at both long distance $(3745 \mathrm{~mm}$; detector far from the sample) and short distance (800 $\mathrm{mm}$; detector close to the sample) in order to achieve the widest possible $q$ range. The samples were measured under vacuum conditions, to reduce air scattering and to increase the mean free path length. The measured curves were corrected for transmission, photon flux and pixel sensitivities of the detector. Dead time correction for the detector and solid angle correction were applied. The magnitude of the $q$ axis is calibrated with a silverbehenate standard sample (1st peak at $q=1.0763 \mathrm{~nm}^{-1}$ ). A glassy carbon standard sample was used to calibrate the SAXS curves into differential scattering cross section units.

UV-vis-NIR spectra were recorded with a Shimadzu UV3102 PC spectrophotometer in a wavelength range from 200 to $3200 \mathrm{~nm}$. Luminescence emission spectra were recorded with a spectrofluorometer RF 5301 PC (Shimadzu, Japan). The luminescence lifetimes were measured for the strongest luminescence transition of $\mathrm{Sm}^{3+}(600 \mathrm{~nm})$ using a custom-made setup. It consists of a pulsed nitrogen laser at $337 \mathrm{~nm}$ (MSG 800, LTB Lasertechnik Berlin, Germany) for excitation, a monochromator (H.25, Jobin Yvon, France) for wavelength selection, a photomultiplier tube (R5929, Hamamatsu, Japan) as a detector and an oscilloscope (TDS2012, Tektronix, USA) for data acquisition. All measurements were conducted at room temperature. 


\section{Results}

The prepared glasses were optically transparent without visible striae. The densities of both glasses were $2.603 \mathrm{~g} \mathrm{~cm}^{-3}$ and equal within the limits of error. The glass transition temperatures determined by dilatometry were $473{ }^{\circ} \mathrm{C}$ and 485 ${ }^{\circ} \mathrm{C}$ for glasses A and B, respectively. Unfortunately, exothermic peaks were not detected by DSC, supposedly due to the small volume concentrations of the formed crystals.

\subsection{XRD and electron microscopy}

In a previous preliminary report, ${ }^{32}$ it has already been shown that the undoped glass is homogeneous, while the Sm-doped glass shows liquid/liquid phase separation. Fig. 1 shows the TEM replica micrographs of the $\mathrm{SmF}_{3}$-doped sample (B) and the undoped sample (A). In the sample with $\mathrm{SmF}_{3}$, heterogeneities are observed with sizes of around $100 \mathrm{~nm}$. Since the non-thermally treated sample is X-ray amorphous (Fig. 2), these heterogeneities are liquid/liquid phase separation with a droplet structure. By contrast, the sample without $\mathrm{SmF}_{3}$ did not show any signs of heterogeneities and hence phase separation. ${ }^{20}$ The droplet size distribution in the $\mathrm{SmF}_{3}$ containing sample (B) is apparently narrow. This sample is transparent for visible light. It would already show notable light scattering in the case of droplets with sizes in the range of $200-400 \mathrm{~nm}$.

The thermally treated samples were also optically transparent. The attributed XRD patterns of samples A and B are shown in Fig. 2. Within the limitations of XRD, both the as-prepared glass samples were amorphous. Both samples heat treated at $580{ }^{\circ} \mathrm{C}$ for $20 \mathrm{~h}$ show similar XRD patterns. Besides an intense and broad background at around $2 \theta=26^{\circ}$ due to a high quantity of amorphous phase, distinct lines attributable to crystalline cubic $\mathrm{BaF}_{2}$ (JCPDS No. 4-452) are observed (marked by asterisks). The lines are notably broadened which is a hint for small crystallites with sizes in the few nm range. The mean crystallite size in the case of sample A is $12.3 \pm 0.5 \mathrm{~nm}$ as calculated from the FWHM of the peaks using Scherrer's equation. For sample B with the addition of a small amount of samarium fluoride, the crystal size is $11.1 \pm 0.4 \mathrm{~nm}$ and hence slightly smaller. The $2 \theta$ values

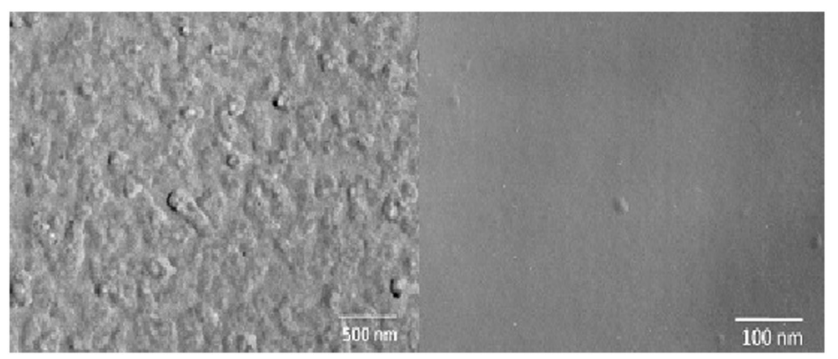

Fig. 1 TEM micrographs (replicas from etched surface) of sample $B$ with $0.05 \mathrm{~mol} \% \mathrm{SmF}_{3}$ (left) and glassy sample A without $\mathrm{SmF}_{3}$ (right) (see also ref. 23).

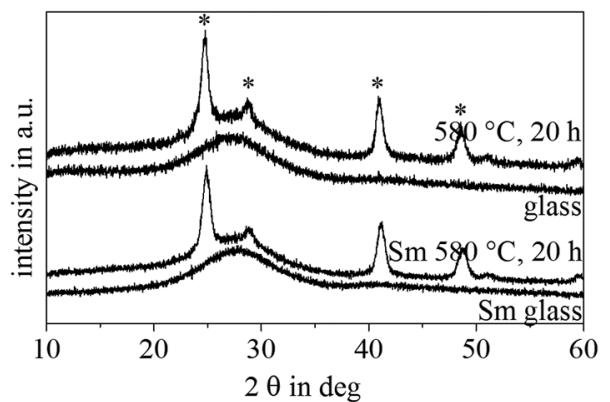

Fig. 2 XRD patterns of the sample without $\mathrm{SmF}_{3}$ (sample A) and the sample with $0.05 \mathrm{~mol}_{\%} \mathrm{SmF}_{3}$ (sample B). Patterns of the as-cast glass and of the samples thermally treated at $580{ }^{\circ} \mathrm{C}$ for $20 \mathrm{~h}$ are shown. The peaks marked by an asterisk are attributed to cubic $\mathrm{BaF}_{2}$ (JCPDS No. 4-452).

of the XRD lines do not differ noticeably and hence the lattice constants are not different within the performed experiment. Thus, the XRD patterns do not allow us to conclude on the incorporation of samarium into the $\mathrm{BaF}_{2}$ lattice.

Fig. 3 presents the TEM micrographs of sample $B$ (with $\mathrm{Sm}$ ), thermally treated at $580^{\circ} \mathrm{C}$ for $20 \mathrm{~h}$. Discrete structures with sizes in the range from 20 to $40 \mathrm{~nm}$ are observed. These structures are homogeneously distributed within the sample.

In Fig. 4, a HAADF micrograph recorded in STEM mode of sample B is shown together with the corresponding EDXS mappings of Sm, Ba and F. Concerning the EDXS mappings of $\mathrm{Ba}$ and $\mathrm{F}$, it is clear that the crystalline structures observed in the HAADF micrographs shown in Fig. 3 and 4 are enriched in $\mathrm{Ba}$ and $\mathrm{F}$. Considering the XRD patterns presented in Fig. 2, the heterogeneities consist of nanocrystalline $\mathrm{BaF}_{2}$. Concerning the EDXS mapping of Sm, a certain enrichment of $\mathrm{Sm}$ in the $\mathrm{BaF}_{2}$ crystals can be stated. Noteworthy is that $\mathrm{SmF}_{3}$ occurs in a concentration of only 0.05 mol\%. Accordingly, the $\mathrm{BaF}_{2}$ crystals should be doped with $\mathrm{Sm}^{3+}$, which is assumed to be incorporated at the $\mathrm{Ba}^{2+}$ sites. Charge compensation should occur via $\mathrm{Ba}^{2+}$ vacancies.

\subsection{Anomalous small-angle $X$-ray scattering}

Fig. 5 (left) shows the SAXS curves calibrated to differential scattering cross sections for sample A, thermally treated at 600 ${ }^{\circ} \mathrm{C}$ for $20 \mathrm{~h}$, and for sample B, crystallized at $580{ }^{\circ} \mathrm{C}$ for $20 \mathrm{~h}$. Both SAXS curves show the same pattern between $0.2<q<3$ $\mathrm{nm}^{-1}$, which indicates the size distribution of the $\mathrm{BaF}_{2}$ nanoparticles. However, the upturn in the SAXS curve (at $q<$ $0.2 \mathrm{~nm}^{-1}$ ) for sample $\mathrm{B}$ (with $\mathrm{Sm}$ ) reveals the formation of additional larger sized particles or aggregates of $\mathrm{BaF}_{2}$ nanoparticles or the formation of surface fractals. The upturn follows the power law of $q^{-3}$.

Further information from the SAXS curves was extracted by fitting the whole shapes of the curves with the spherical core shell model in combination with the Gaussian size distribution of particles, using the software SASfit. The evaluated fitting parameters on the particle core size and 


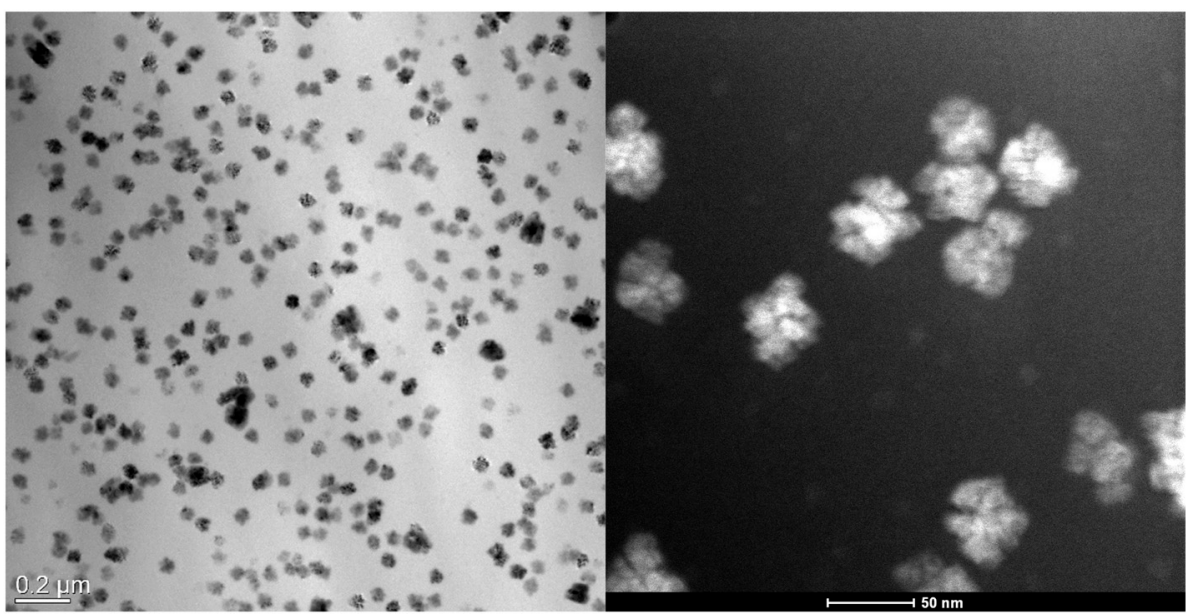

Fig. 3 TEM micrograph of sample B annealed for $20 \mathrm{~h}$ at $580^{\circ} \mathrm{C}$. Left: Bright field image, right: HAADF image in a higher magnification.

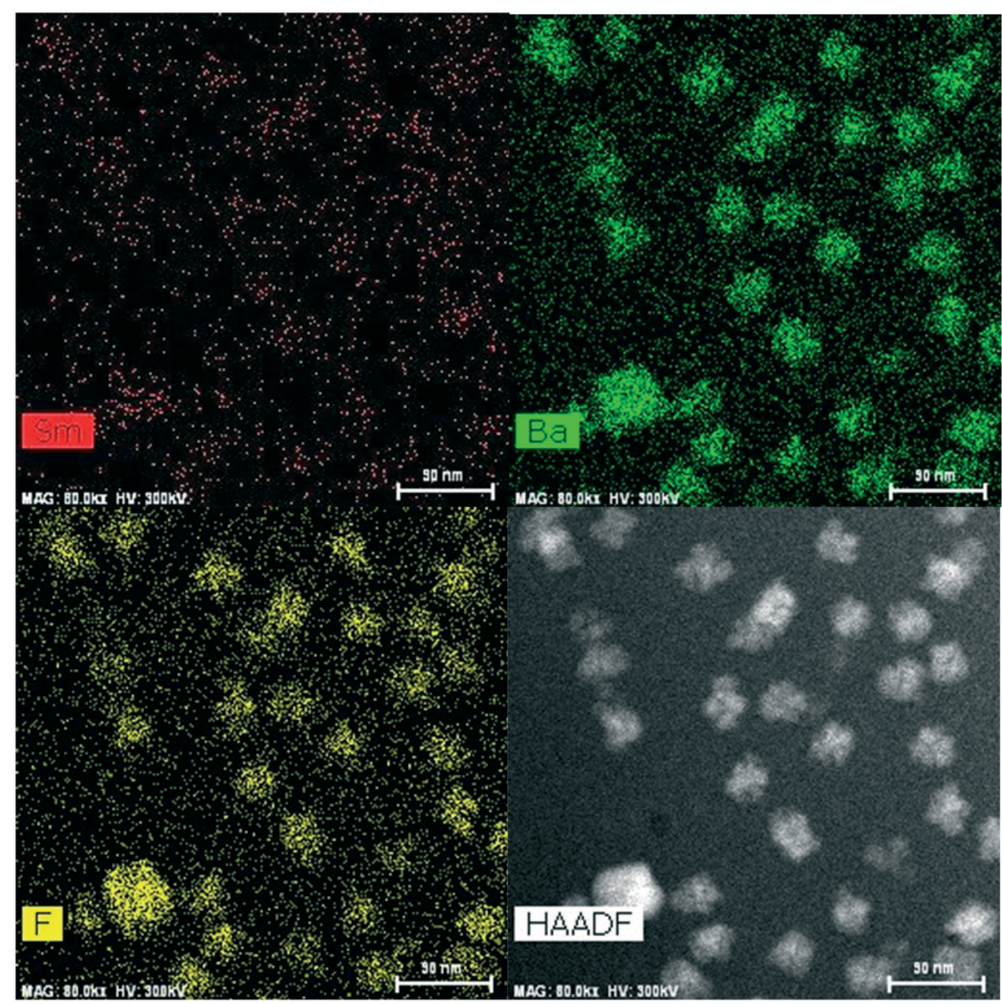

Fig. 4 HAADF micrograph (bottom right) taken in STEM mode of sample $\mathrm{B}$, thermally treated for $20 \mathrm{~h}$ at $580{ }^{\circ} \mathrm{C}$ and the corresponding EDXS mappings of Sm (top left), Ba (top right) and F (bottom left).

shell thickness are given in Table 2. The distribution of the core $\left(\mathrm{BaF}_{2}\right)$ particles in both samples is shown in Fig. 5 (right). The volume weighted mean diameters are fairly similar and centred at $11.2 \mathrm{~nm}$ for crystallized sample A and at $11.0 \mathrm{~nm}$ for sample B (Table 2). The thicknesses of the shells are 2.7 and $2.5 \mathrm{~nm}$, respectively.

ASAXS measurements were conducted to reveal the elemental distribution of $\mathrm{Ba}$ atoms in the core, the composition of the shell and the densities of the core, shell and the remaining glass matrix. ASAXS experiments were performed on sample A and sample B near the Ba X-ray absorption edge (5247 eV), more precisely at the 4 energies: 4900, 5177, 5234 and $5244 \mathrm{eV}$ (Fig. 6). Both samples show significant contrast variations (ASAXS effect) near the Ba absorption edge, which indicates the presence of Ba atoms in the nanoparticles, evidencing the core shell structure.

The contrast variation values from the ASAXS curves were evaluated by fitting them with a spherical core shell model 

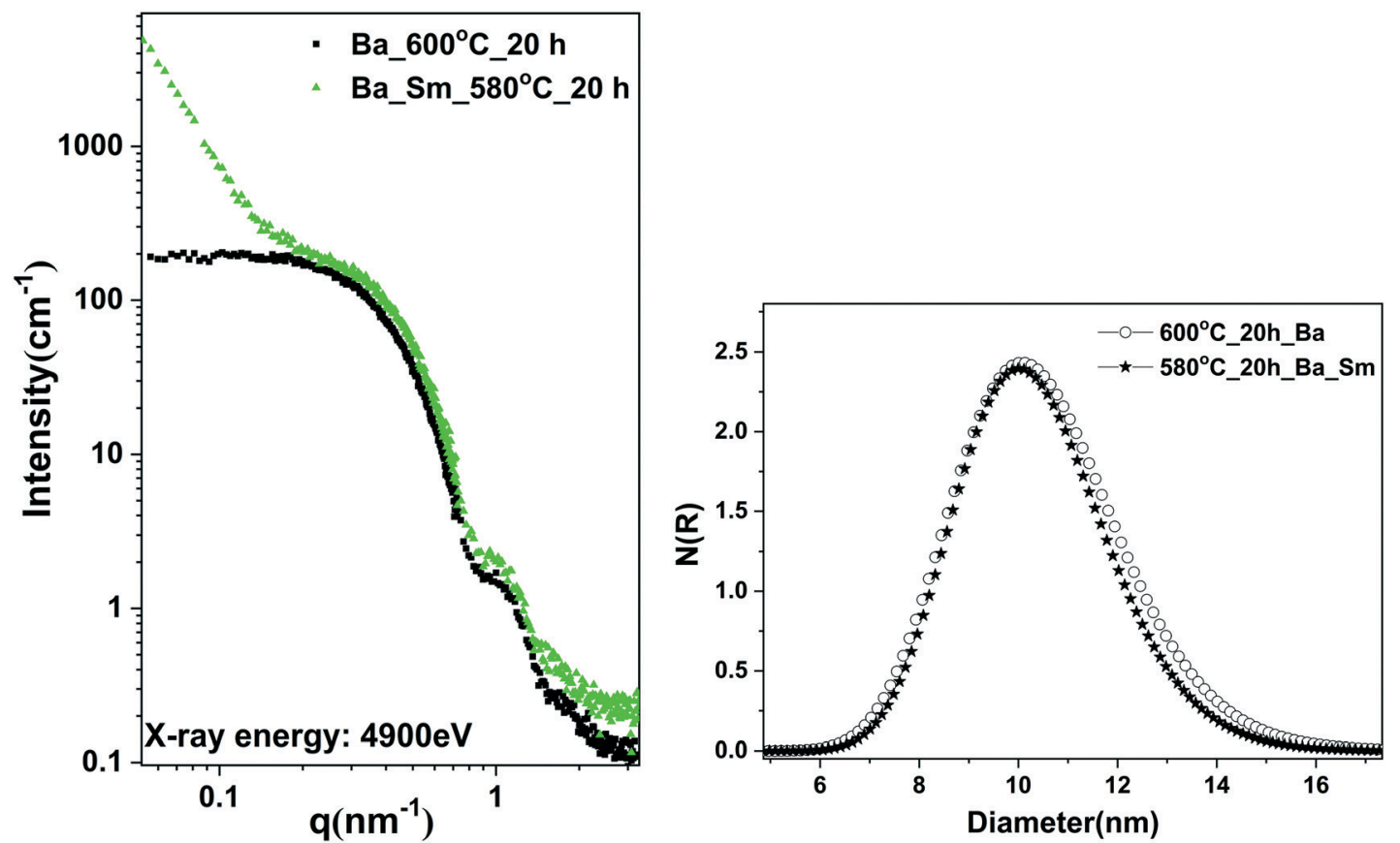

Fig. 5 Left: SAXS scattering curves recorded from the annealed samples A and B using an energy of 4900 eV. Right: Size distributions of the core of the particles. Sample A was crystallized at $600^{\circ} \mathrm{C}$ for $20 \mathrm{~h}$; sample B was crystallized at $580^{\circ} \mathrm{C}$ for $20 \mathrm{~h}$.

using the SASfit program and a procedure published previously. ${ }^{20}$ Fitting the experimentally evaluated contrast values with the theoretically calculated values reveals the chemical composition and densities of the core, shell and the remaining glass matrix. The evaluated parameters are provided in Table 2.

Since the scattering curves strongly depend on the energy near the Ba-absorption edge, the particles that give rise to $\mathrm{X}$-ray scattering are strongly enriched in Ba. According to the XRD patterns, they consist of $\mathrm{BaF}_{2}$. Therefore, the scattering curves were fitted assuming a $\mathrm{BaF}_{2}$ core and an $\mathrm{SiO}_{2}$ shell.

\subsection{Spectroscopic measurements}

Fig. 7 shows the UV-vis-NIR transmission spectra of the Smdoped glass (B), not annealed (black curve) and thermally annealed at $580^{\circ} \mathrm{C}$ for $20 \mathrm{~h}$ (red curve). In the spectral range from 1000 to $3200 \mathrm{~nm}$, the spectra are practically identical and show the absorption lines typical for $\mathrm{Sm}^{3+}$ containing

Table 2 Core radii, shell thicknesses, densities and volume fractions of sample A and sample B crystallized for $20 \mathrm{~h}$ at 600 and $580{ }^{\circ} \mathrm{C}$, respectively

\begin{tabular}{lll}
\hline & Sample A & Sample B \\
\hline Total particle radius in $\mathrm{nm}$ & 8.4 & 8.0 \\
Core radius in nm & 5.6 & 5.5 \\
Shell thickness in nm & 2.7 & 2.5 \\
Density of the core in $\mathrm{g} \mathrm{cm}^{-3}$ & 4.5 & 4.5 \\
Density of the shell in $\mathrm{g} \mathrm{cm}^{-3}$ & 2.3 & 2.3 \\
Density of the matrix in $\mathrm{g} \mathrm{cm}^{-3}$ & 2.4 & 2.4
\end{tabular}

glasses. The wavelength and line widths attributed to the absorption lines did not obviously change noticeably during crystallization. At wavelengths in the range from 350 to 1000 $\mathrm{nm}$, the transmission of the crystallized sample is somewhat smaller. The difference between the two curves increases with decreasing wavelength. This is a hint for a small extent of light scattering. The transmission at wavelengths of 350 and $500 \mathrm{~nm}$ of sample A is around 82 and $92 \%$, while it is 70 and $87 \%$ for sample B, respectively. For most potential applications (besides as an active laser component for the visible range), the slight scattering is not of importance. For example, as light converters for blue LEDs to produce white light, slight scattering is not disadvantageous, and also for the use as an active laser material in the infrared, scattering of visible light does not have a negative effect.

Fig. 8 shows the luminescence emission spectra (excitation at $402 \mathrm{~nm}$ ) of the prepared glass B and sample B crystallized at $580{ }^{\circ} \mathrm{C}$ for $20 \mathrm{~h}$ in a wavelength range from 250 to $600 \mathrm{~nm}$. Four emission lines typical for $\mathrm{Sm}^{3+}$ are observed at $562 \mathrm{~nm}:{ }^{4} \mathrm{G}_{5 / 2} \rightarrow{ }^{6} \mathrm{H}_{5 / 2}$, at $600 \mathrm{~nm}:{ }^{4} \mathrm{G}_{5 / 2} \rightarrow{ }^{6} \mathrm{H}_{7 / 2}$, at $645 \mathrm{~nm}:{ }^{4} \mathrm{G}_{5 / 2} \rightarrow{ }^{6} \mathrm{H}_{9 / 2}$ and at $706 \mathrm{~nm}:{ }^{4} \mathrm{G}_{5 / 2} \rightarrow{ }^{6} \mathrm{H}_{11 / 2}$. The most intense emission band was observed at $600 \mathrm{~nm}$ and the second most intense one at $645 \mathrm{~nm}$, corresponding to the transitions ${ }^{4} \mathrm{G}_{5 / 2} \rightarrow{ }^{6} \mathrm{H}_{7 / 2}$ (orange) and ${ }^{4} \mathrm{G}_{5 / 2} \rightarrow{ }^{6} \mathrm{H}_{9 / 2}$ (red), respectively. The emission spectra of the glass and the crystallized sample do not differ much. All lines are located at the same wavelengths and the intensities are approximately the same.

The semi-logarithmic plots of the luminescence emission decay curves of the ${ }^{4} \mathrm{G}_{5 / 2} \rightarrow{ }^{6} \mathrm{H}_{5 / 2}$ emission are shown in Fig. 9 for the as-cast sample B and samples with composition 

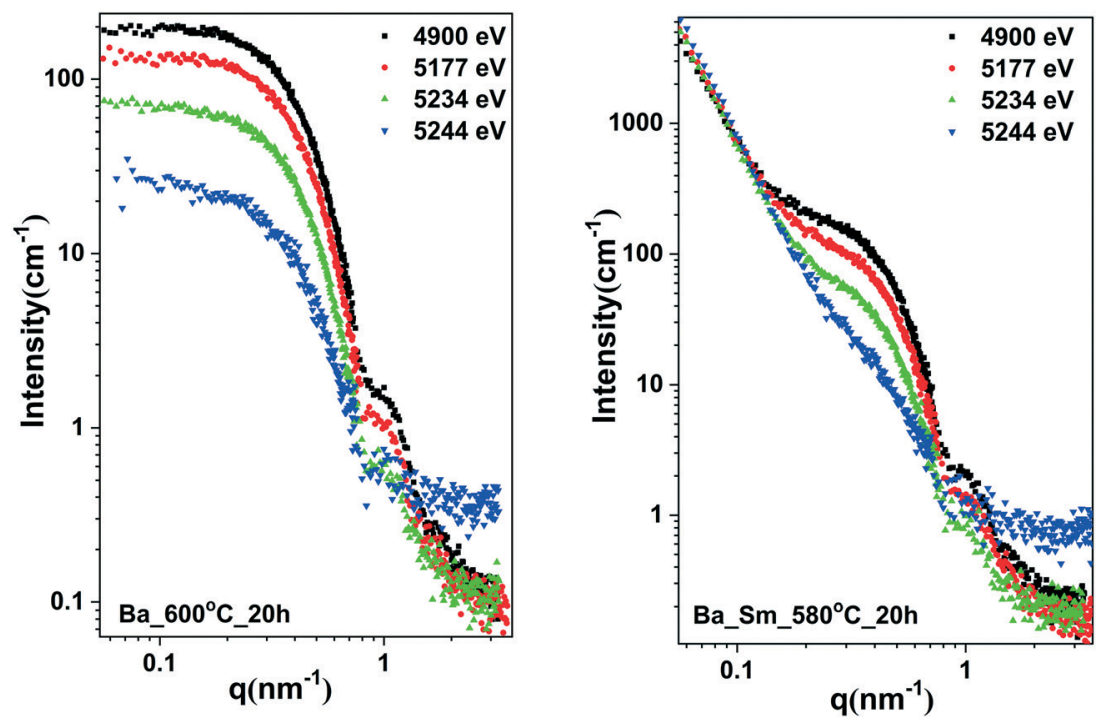

Fig. 6 ASAXS scattering curves recorded from sample A annealed at $600{ }^{\circ} \mathrm{C}$ for $20 \mathrm{~h}$ (right) and sample B annealed at $580{ }^{\circ} \mathrm{C}$ for $20 \mathrm{~h}$ (left) using $\mathrm{X}$-ray energies close to the absorption edge of $\mathrm{Ba}$. The X-ray energies used are 4900, 5177, 5234 and $5244 \mathrm{eV}$.

B crystallized at $520{ }^{\circ} \mathrm{C}$ for $20 \mathrm{~h}$ and at $580{ }^{\circ} \mathrm{C}$ for $20 \mathrm{~h}$. Additionally, a decay curve for an almost pure fluoride glass (in the literature usually denoted as FP03) with a composition of $10 \mathrm{MgF}_{2}, 28 \mathrm{CaF}_{2}, 23 \mathrm{SrF}_{2}, 36 \mathrm{AlF}_{3}$, and $3 \mathrm{Sr}\left(\mathrm{PO}_{3}\right)_{2}$ is shown for comparison. All the samples have the same doping concentration of $\mathrm{Sm}^{3+}$ of $1 \times 10^{19} \mathrm{Sm}^{3+}$ per $\mathrm{cm}^{3}$. These curves provide information on the lifetime of the ${ }^{4} \mathrm{G}_{5 / 2}$ excited state of the rare-earth ion in the respective host glass composition. A straight line in the semi-logarithmic scale represents a mono-exponential decay. The slope of these lines represents the reciprocal luminescence lifetimes. For all the studied samples, an approximately mono-exponential decay is observed, which indicates homogeneously distributed $\mathrm{Sm}^{3+}$ ions and low concentration quenching. The luminescence lifetimes of the studied samples and the fluoride phosphate glass sample FP03 for comparison are summarized in Table 3. The lifetimes of the investigated samples are somewhat shorter than that for the fluoride phosphate sample, an almost pure fluoride glass.

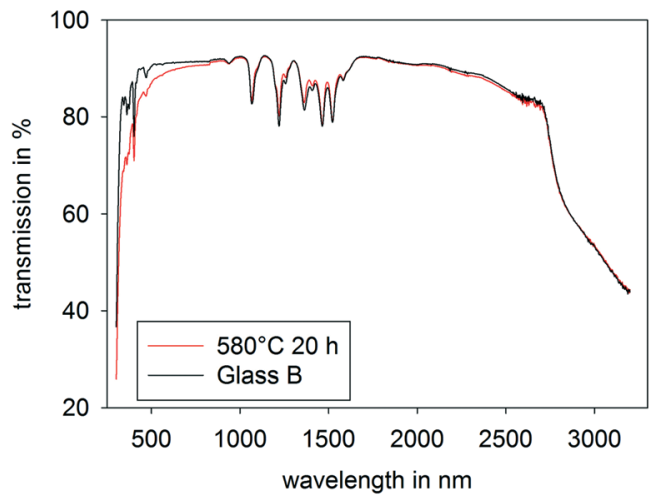

Fig. 7 UV-vis-NIR transmission spectra of the as-cast glass B (black) and glass $\mathrm{B}$ after thermal treatment at $580^{\circ} \mathrm{C}$ for $20 \mathrm{~h}$ (red).

\section{Discussion}

Although glass B contains only $0.05 \mathrm{~mol}_{0} \mathrm{SmF}_{3}$, the structure was very different from that of the sample without samarium (glass A). While the glass doped with samarium showed phase separation with droplets with sizes of around $100 \mathrm{~nm}$, the glass without samarium did not. Thermal treatment leads to the crystallization of cubic $\mathrm{BaF}_{2}$ in both glasses. The XRD patterns show strongly broadened lines attributed to mean crystallite sizes of around $11 \mathrm{~nm}$, as calculated from the XRD line broadening. These crystallite sizes are comparable with the size of the crystals observed in the TEM micrographs. The effect of time and temperature on the size of the crystals is comparably small as already discussed in ref. 12. However, the effect is notably more pronounced than in previously studied glasses, in which during annealing, $\mathrm{CaF}_{2}$ is precipitated. ${ }^{11,27}$ For sample A, previous studies using advanced TEM measurements gave evidence of the formation of core shell structures. ${ }^{20}$ Using SAXS and ASAXS, the existence of such a shell is confirmed. In the $\mathrm{SmF}_{3}$-doped sample annealed at $580{ }^{\circ} \mathrm{C}$ for $20 \mathrm{~h}$, SAXS and

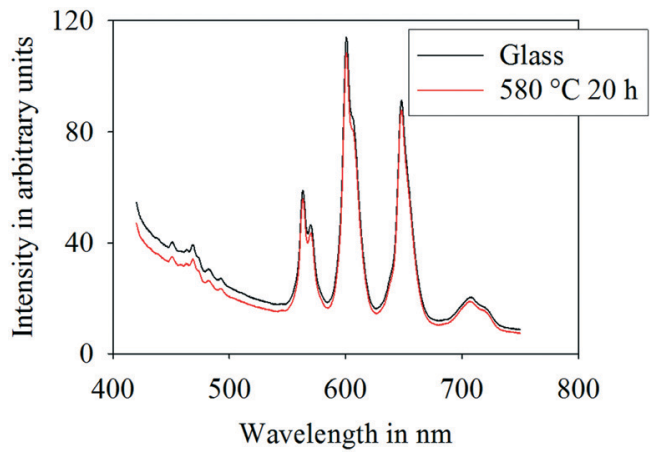

Fig. 8 Luminescence emission spectra of the as-cast glass B (black) and glass B thermally treated at $580^{\circ} \mathrm{C}$ for $20 \mathrm{~h}$ (red). 


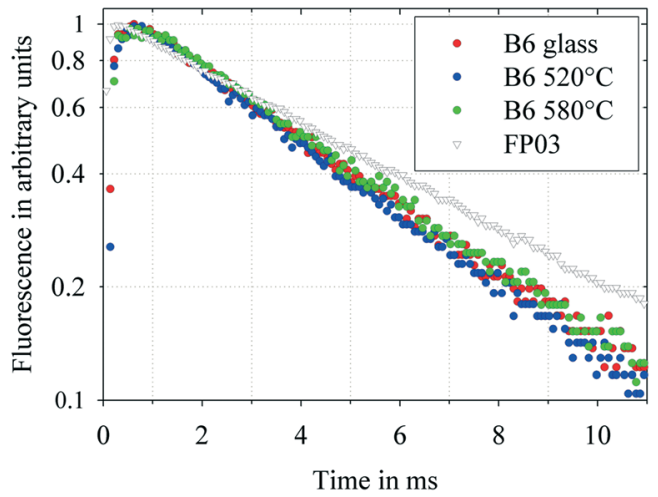

Fig. 9 Semi-logarithmic luminescence decay curves at $600 \mathrm{~nm}$ of the as-cast sample $B$ and samples with composition $B$ thermally treated at $520{ }^{\circ} \mathrm{C}$ for $20 \mathrm{~h}$ and at $580{ }^{\circ} \mathrm{C}$ for $20 \mathrm{~h}$, as well as of an almost pure fluoride glass, FP03, for comparison.

Table 3 Luminescence lifetimes of the glass B and crystallized samples in comparison to the fluoride phosphate glass FP03

\begin{tabular}{lll}
\hline & Thermal treatment & Luminescence lifetime (ms) \\
\hline Glass B & No & 4.89 \\
Glass B & $520^{\circ} \mathrm{C} / 20 \mathrm{~h}$ & 4.60 \\
Glass B & $580^{\circ} \mathrm{C} / 20 \mathrm{~h}$ & 4.97 \\
FP03 & No & 6.20
\end{tabular}

ASAXS also show a core shell structure. In both cases, the shell is enriched in $\mathrm{SiO}_{2}$ and hence is attributed to a layer of higher viscosity with respect to the matrix. The size of the $\mathrm{BaF}_{2}$ cores is around $11 \mathrm{~nm}$ and approximately the same for both glasses A and $\mathrm{B}$. The crystallite sizes as determined by XRD line broadening are 12.3 and $11.1 \mathrm{~nm}$, for samples $\mathrm{A}$ and $\mathrm{B}$, respectively. In this context, it should be noted that XRD measures the size of a particle with translational symmetry. SAXS and ASAXS analyse the whole shape of a small-angle scattering curve to obtain size distributions of regions having almost the same electron density and mean chemical composition, and do not require only crystalline regions. If a periodic lattice has a highly distorted outer layer (but approximately the same chemical composition), then XRD determines the periodic size. SAXS would determine the size including a distorted layer as an example. Hence, it cannot be expected that exactly the same results from these two methods are obtained.

This is surprising because the as-melted glass A is not phase separated, while glass B shows phase separation. It can be assumed that in both cases, the shell acts as a diffusion barrier which hinders further crystal growth. In the case of sample B, first, a liquid droplet enriched in barium, fluoride, $\mathrm{SiO}_{2}$ and possibly $\mathrm{Al}_{2} \mathrm{O}_{3}$ is formed. During the course of the crystallization, $\mathrm{BaF}_{2}$ is formed inside the droplet and $\mathrm{SiO}_{2}$ as well as possibly $\mathrm{Al}_{2} \mathrm{O}_{3}$ is expelled. It should be noted that stresses appear simultaneously with the formation of the core shell structure. These stresses can hardly relax because the composition of the shell is attributed to a higher glass transition temperature which is above the crystallization temperature applied.
It is remarkable that addition of a $\mathrm{SmF}_{3}$ concentration as small as $0.05 \mathrm{~mol} \%$ gives rise to drastic changes in the crystallization mechanism. It should further be mentioned that similar structures, in our case $\mathrm{BaF}_{2}$ nanocrystals with $\mathrm{SiO}_{2}$ enriched shells, do not allow us to conclude on similar crystallization mechanisms.

It is further surprising that the luminescence lifetimes for a $\mathrm{Sm}^{3+}$ emission at $600 \mathrm{~nm}$ are in the range of $5 \mathrm{~ms}$. This is much longer than those in silicate glasses, which usually show luminescence lifetimes of about 2-3 ms depending on their chemical composition..$^{28,32,33}$ For aluminosilicate glasses, fluorescence lifetimes are in the range of 2.2 to 3.8 $\mathrm{ms},{ }^{28,29}$ while for tellurite glasses, 0.6 to $1.8 \mathrm{~ms}$ (ref. 30) and for $\mathrm{ZnO}-\mathrm{Al}_{2} \mathrm{O}_{3}-\mathrm{BaO}-\mathrm{B}_{2} \mathrm{O}_{3}$ glasses, 0.9 to $2.7 \mathrm{~ms}$ (ref. 31) were determined. Up to now, only fluoride phosphate glasses have been reported to possess longer fluorescence lifetimes. Most probably, the coordination of $\mathrm{Sm}^{3+}$ by fluoride leads to a notable increase in the fluorescence lifetime. These fluoride phosphate glasses are very difficult to prepare in high homogeneity, while oxyfluorosilicate glasses are much easier to prepare. In the case of the phase separated glass B, both $\mathrm{Sm}$ and fluoride are enriched in the droplet phase which should favor the coordination of $\mathrm{Sm}^{3+}$ with fluoride. Long lifetimes are generally observed in fluoride glasses, however, at similar doping concentrations, their lifetimes are even somewhat longer. ${ }^{32}$ Two conclusions can be drawn from these observations: firstly, the $\mathrm{Sm}^{3+}$ ions are incorporated into a fluoride rich environment in the investigated samples, probably the fluoride rich droplets formed by phase separation. The somewhat shorter luminescence lifetime could be a hint to an increased local $\mathrm{Sm}^{3+}$ concentration and therefore could result from slight concentration quenching. Earlier investigations show that similar lifetimes of about 5 $\mathrm{ms}$ were measured for fluoride glasses with a doping concentration of $1 \times 10^{20} \mathrm{Sm}^{3+}$ per $\mathrm{cm}^{3}{ }^{32}$ This would imply that $\mathrm{Sm}^{3+}$ is accumulated in the droplets. Indeed, it is well known that rare earth ions prefer a fluoride rich environment over a silicate phase. ${ }^{34,35}$

The melting of glasses, with high fluoride concentrations such as fluoride phosphate glasses, however, is a serious technological challenge and a high homogeneity is very difficult to achieve, because of heavy fluoride evaporation. Hence, the preparation of fluoride containing nanoglass ceramics with similar spectroscopic properties is advantageous because they are much easier to produce.

It should be noted that the luminescence of transition or rare earth cations is an effect also observed in liquids and hence, not necessarily connected to the solid state. By contrast to luminescence caused by nano-size semiconductors, nano-size effects of rare earth containing compounds have never been reported.

\section{Conclusions}

Using X-ray diffraction, transmission electron microscopy and anomalous small-angle X-ray scattering, a glass with the 
mol\% composition $1.88 \quad \mathrm{Na}_{2} \mathrm{O} \cdot 15.04 \quad \mathrm{~K}_{2} \mathrm{O} \cdot 7.52 \quad \mathrm{Al}_{2} \mathrm{O}_{3} \cdot 69.56$ $\mathrm{SiO}_{2} \cdot 6.00 \mathrm{BaF}_{2}$ and a glass doped with only $0.05 \mathrm{~mol} \% \mathrm{SmF}_{3}$ were studied. While the undoped glass was homogeneous, the samarium doped glass showed droplet phase separation with a droplet size of around $100 \mathrm{~nm}$ as proved by TEM. Thermal treatment of the samples led to the crystallization of cubic $\mathrm{BaF}_{2}$. ASAXS gave evidence of a core shell structure. The spherical particles of the undoped and the doped samples had diameters of around $11 \mathrm{~nm}$, while the shell had a thickness of $2.6 \mathrm{~nm}$. Surprisingly, both the cores and the shells possess hence similar dimensions if crystallized from the homogeneous glass and the phase separated glass. It should be noted, however, that the origin of the barrier is very different. In both cases, it is assumed that the shell acts as a diffusion barrier that hinders crystal growth. The core sizes determined by ASAXS were in excellent agreement with the crystallite sizes calculated from the strongly broadened XRD lines using Scherrer's equation. The samarium doped sample shows strong luminescence. The luminescence lifetimes were nearly $5 \mathrm{~ms}$ at $600 \mathrm{~nm}$ and hence unusually long.

\section{Conflicts of interest}

The authors declare no conflict of interest.

\section{Acknowledgements}

We thank HZB for the allocation of synchrotron radiation beamtime for the ASAXS instrument at the 7T-MPW-SAXS beamline at BESSY II.

\section{References}

1 G. H. Beall and L. R. Pinckney, Nanophase Glass-Ceramics, J. Am. Ceram. Soc., 1999, 82, 5-16.

2 M. J. Dejneka, The luminescence and structure of novel transparent oxyfluoride glass-ceramics, J. Non-Cryst. Solids, 1998, 239, 149-155.

3 M. Mortier, A. Monteville, G. Patriarche, G. Maze and F. Auzel, New progresses in transparent rare-earth doped glassceramics, Opt. Mater., 2001, 16, 255-267.

4 Y. Yu, D. Chen, Y. Wang, F. Liu and E. Ma, A new transparent oxyfluoride glass ceramic with improved luminescence, J. Non-Cryst. Solids, 2007, 353, 405-409.

5 S. Hendy, Light scattering in transparent glass ceramics, Appl. Phys. Lett., 2002, 81, 1171-1173.

6 A. Edgar, Core-shell particle model for optical transparency in glass ceramics, Appl. Phys. Lett., 2006, 89, 041909.

7 C. Patzig, T. Höche, M. Dittmer and C. Rüssel, Temporal Evolution of Crystallization in $\mathrm{MgO}-\mathrm{Al}_{2} \mathrm{O}_{3}-$ $\mathrm{SiO}_{2}-\mathrm{ZrO}_{2}$ Glass Ceramics, Cryst. Growth Des., 2012, 12, 2059-2067.

8 C. Bocker, C. Rüssel and I. Avramov, Transparent Nano Crystalline Glass-Ceramics by Interface Controlled Crystallization, Int. J. Appl. Glass Sci., 2013, 4, 174-181.
9 C. Bocker, I. Avramov and C. Rüssel, Viscosity and diffusion of barium and fluoride in $\mathrm{Na}_{2} \mathrm{O} / \mathrm{K}_{2} \mathrm{O} / \mathrm{Al}_{2} \mathrm{O}_{3} / \mathrm{SiO}_{2} / \mathrm{BaF}_{2}$ glasses, Chem. Phys., 2010, 369, 96-100.

10 K. Shinozaki, T. Honma, K. Oh-ishi and T. Komatsu, Morphology of $\mathrm{CaF}_{2}$ nanocrystals and elastic properties in transparent oxyfluoride crystallized glasses, Opt. Mater., 2011, 33, 1350-1356.

11 C. Rüssel, Nanocrystallization of $\mathrm{CaF}_{2}$ from $\mathrm{Na}_{2} \mathrm{O} / \mathrm{K}_{2} \mathrm{O} / \mathrm{CaO} /$ $\mathrm{CaF}_{2} / \mathrm{Al}_{2} \mathrm{O}_{3} / \mathrm{SiO}_{2}$ Glasses, Chem. Mater., 2005, 17, 5843-5847.

12 C. Bocker and C. Rüssel, Self-organized nano-crystallisation of $\mathrm{BaF}_{2}$ from $\mathrm{Na}_{2} \mathrm{O} / \mathrm{K}_{2} \mathrm{O} / \mathrm{BaF}_{2} / \mathrm{Al}_{2} \mathrm{O}_{3} / \mathrm{SiO}_{2}$ glasses, J. Eur. Ceram. Soc., 2009, 29, 1221-1225.

13 R. Wurth and C. Rüssel, The crystallization of $(\mathrm{Pb}, \mathrm{Yb}, \mathrm{Er}) \mathrm{F}_{\mathrm{x}}$ nano particles from glasses with the composition 20 $\mathrm{SiO}_{2} \cdot 13.5 \mathrm{~B}_{2} \mathrm{O}_{3} \cdot 6 \mathrm{Al}_{2} \mathrm{O}_{3} \cdot 10 \mathrm{PbO} \cdot 6.6 \mathrm{CdO} 20 \mathrm{PbF}_{2} \cdot 13.3 \mathrm{CdF}_{2} \cdot 10$ $\mathrm{YbF}_{3} \cdot 0.5 \mathrm{ErF}_{3}$, Solid State Sci., 2011, 13, 1132-1136.

14 C. Bocker, I. Avramov and C. Rüssel, The effect of stresses during crystallization on the crystallite size distributions, J. Eur. Ceram. Soc., 2011, 31, 2861-2866.

15 C. Bocker, S. Bhattacharyya, T. Höche and C. Rüssel, Size distribution of $\mathrm{BaF}_{2}$ nanocrystallites in transparent glass ceramics, Acta Mater., 2009, 57, 5956-5963.

16 C. Bocker, I. Avramov and C. Rüssel, Experimental evidence of high pressure during crystallization of glass - The formation of an orthorhombic high-pressure $\mathrm{BaF}_{2}$ phase, Scr. Mater., 2010, 62, 814-817.

17 E. Kleebusch, C. Rüssel, C. Patzig and T. Höche, Evidence of epitaxial growth of high-quartz solid solution on $\mathrm{ZrTiO}_{4}$ nuclei in a $\mathrm{Li}_{2} \mathrm{O}-\mathrm{Al}_{2} \mathrm{O}_{3}-\mathrm{SiO}_{2}$ glass, J. Alloys Compd., 2018, 748, 73-79.

18 A. de Pablos-Martín, F. Muñoz, G. C. Mather, C. Patzig, S. Bhattacharyya, J. R. Jinschek, Th. Höche, A. Durán and M. J. Pascual, $\mathrm{KLaF}_{4}$ Nanocrystallisation in Oxyfluoride GlassCeramics, CrystEngComm, 2013, 15, 10323-10332.

19 A. de Pablos-Martin, C. Patzig, Th. Höche, A. Duran and M. J. Pascual, Distribution of Thulium in $\mathrm{Tm}^{3+}$-Doped Oxyfluoride Glasses and Glass-Ceramics, CrystEngComm, 2013, 15, 6979-6985.

20 V. S. Raghuwanshi, A. Hoell, C. Bocker and C. Rüssel, Experimental evidence of a diffusion barrier around $\mathrm{BaF}_{2}$ nanocrystals in a silicate glass system by ASAXS, CrystEngComm, 2012, 14, 5215.

21 S. Bhattacharyya, T. Höche, N. Hemono, M. J. Pascual and P. A. van Aken, Nano-crystallization in $\mathrm{LaF}_{3}-\mathrm{Na}_{2} \mathrm{O}-\mathrm{Al}_{2} \mathrm{O}_{3}-\mathrm{SiO}_{2}$ glass, J. Cryst. Growth, 2009, 311, 4350-4355.

22 C. Bocker, J. Wiemert and C. Rüssel, The formation of strontium fluoride nano crystals from a phase separated silicate glass, J. Eur. Ceram. Soc., 2013, 33, 1737-1745.

23 J. R. Barros, C. Bocker and C. Rüssel, The effect of $\mathrm{Er}^{3+}$ and $\mathrm{Sm}^{3+}$ on phase separation and crystallization in $\mathrm{Na}_{2} \mathrm{O} / \mathrm{K}_{2} \mathrm{O}$ / $\mathrm{BaF}_{2} / \mathrm{BaO} / \mathrm{Al}_{2} \mathrm{O}_{3} / \mathrm{SiO}_{2}$ glasses, Solid State Sci., 2010, 12, 2086-2090.

24 V. S. Raghuwanshi, C. Rüssel and A. Hoell, Crystallization of $\mathrm{ZrTiO}_{4}$ Nanocrystals in Lithium-Alumino-Silicate Glass Ceramics: Anomalous Small-Angle X-ray Scattering Investigation, Cryst. Growth Des., 2014, 14, 2838-2845. 
25 W. Vogel, Glass Chemistry, Springer, Berlin, 1994.

26 T. Höche, J. W. Gerlach and T. Petsch, Static-Charging Mitigation and Contamination Avoidance by Selective Carbon Coating of TEM Samples, Ultramicroscopy, 2006, 106, 981-985.

27 A. Hoell, Z. Varga, V. S. Raghuwanshi, M. Krumrey, C. Bocker and C. Rüssel, ASAXS study of $\mathrm{CaF}_{2}$ nanoparticles embedded in a silicate glass matrix, J. Appl. Crystallogr., 2014, 47, 60-66.

28 A. Herrmann, M. Tewelde, S. Kuhn, M. Tiegel and C. Rüssel, The Effect of Glass Composition on the Luminescence Properties of $\mathrm{Sm}^{3+}$ doped Alumino Silicate Glasses, J. NonCryst. Solids, 2018, 502, 190-197.

29 R. Turki, M. Zekri, A. Herrmann, C. Rüssel, R. Maalej and K. Damak, Optical properties of peralkaline aluminosilicate glasses doped with $\mathrm{Sm}^{3+}$, J. Alloys Compd., 2019, 806, 1339-1347.

30 P. Yasaka, R. Rajaramakrishna, W. Wongwan, P. Yamchumporn, H. J. Kim and J. Kaewkhao, Development of $\mathrm{ZnO}-\mathrm{BaO}-\mathrm{B}_{2} \mathrm{O}_{3}-\mathrm{TeO}_{2}$ glass doped with $\mathrm{Sm}^{3+}$ for orange emitting material, Solid State Sci., 2019, 98, 106041.
31 L. Yuliantini, R. Hidayat, M. Djamal, K. Boonin, P. Yasaka, E. Kaewnuam and J. Kaewkhao, Development of $\mathrm{Sm}^{3+}$ doped $\mathrm{ZnO}-\mathrm{Al}_{2} \mathrm{O}_{3}-\mathrm{BaO}-\mathrm{B}_{2} \mathrm{O}_{3}$ glasses for optical gain medium, J. NonCryst. Solids, 2018, 482, 86-92.

32 A. Herrmann and D. Ehrt, Time-resolved fluorescence measurements on $\mathrm{Dy}^{3+}$ and $\mathrm{Sm}^{3+}$ doped glasses, J. Non-Cryst. Solids, 2008, 354, 916-926.

33 D. Ehrt, H. T. Vu, A. Herrmann and G. Völksch, Luminescent $\mathrm{ZnO}-\mathrm{Al}_{2} \mathrm{O}_{3}-\mathrm{SiO}_{2}$ glasses and glass ceramics, Adv. Mater. Res., 2008, 39(40), 231-236.

34 A. Herrmann, M. Tylkowski, C. Bocker and C. Rüssel, Preparation and Luminescence Properties of Glass-Ceramics Containing $\mathrm{Sm}^{3+}$-Doped Hexagonal $\mathrm{NaGdF}_{4}$ Crystals, J. Mater. Sci., 2013, 48, 6262-6268.

35 A. Herrmann, M. Tylkowski, C. Bocker and C. Rüssel, Cubic and Hexagonal $\mathrm{NaGdF}_{4}$ Crystals Precipitated from an Aluminosilicate Glass: Preparation and Luminescence Properties, Chem. Mater., 2013, 25, 2878-2884. 